\title{
Correlated Calcium Uptake and Release by Mitochondria and Endoplasmic Reticulum of CA3 Hippocampal Dendrites after Afferent Synaptic Stimulation
}

\author{
Natalia B. Pivovarova, ${ }^{1 *}$ Lucas D. Pozzo-Miller, ${ }^{2,3 *}$ Jarin Hongpaisan, ${ }^{1}$ and S. Brian Andrews ${ }^{1,3}$ \\ 1 Laboratory of Neurobiology, National Institute of Neurological Disorders and Stroke, National Institutes of Health, \\ Bethesda, Maryland 20892-4062, 2Department of Neurobiology and Civitan International Research Center, University of \\ Alabama at Birmingham, Birmingham, Alabama 35294-0021, and ${ }^{3}$ The Marine Biological Laboratory, Woods Hole, \\ Massachusetts 02543
}

\begin{abstract}
Mitochondria and endoplasmic reticulum (ER) are important modulators of intracellular calcium signaling pathways, but the role of these organelles in shaping synaptic calcium transients in dendrites of pyramidal neurons remains speculative. We have measured directly the concentrations of total $\mathrm{Ca}$ (bound plus free) within intracellular compartments of proximal dendrites of CA3 hippocampal neurons at times after synaptic stimulation corresponding to the peak of the cytoplasmic free $\mathrm{Ca}^{2+}$ transient (1 $\mathrm{sec})$, to just after its decay ( $30 \mathrm{sec})$, and to well after its return to prestimulus levels (180 sec). Electron probe microanalysis of cryosections from rapidly frozen slice cultures has revealed that afferent mossy fiber stimulation evokes large, rapid elevations in the concentration of total mitochondrial $\mathrm{Ca}\left([\mathrm{Ca}]_{\text {mito }}\right)$ in depolarized dendrites. A single tetanus $(50 \mathrm{~Hz} / 1 \mathrm{sec})$ elevated $[\mathrm{Ca}]_{\text {mito }}$ more than fivefold above characteristically low basal levels within $1 \mathrm{sec}$ of stimulation and $>10$-fold by $30 \mathrm{sec}$ after stimulation. This
\end{abstract}

Mitochondria and the endoplasmic reticulum (ER) are the main organellar components of a cellular calcium regulatory system that is essential for shaping intracellular calcium signals. Although the importance of the ER has been recognized for decades (for review, see Berridge, 1998; Meldolesi, 2001), our understanding of the role of mitochondrial $\mathrm{Ca}^{2+}$ transport recently has undergone considerable evolution (Friel, 2000; Pozzan and Rizzuto, 2000). There is now accumulating evidence that in a variety of cell types, including neurons, elevation of the free cytosolic $\mathrm{Ca}^{2+}$ concentration $\left(\left[\mathrm{Ca}^{2+}\right]_{\mathrm{i}}\right.$ ) leads to mitochondrial $\mathrm{Ca}^{2+}$ uptake and that this has a major impact on $\mathrm{Ca}^{2+}$ signaling (Babcock and Hille, 1998; Duchen, 1999; Pozzan and Rizzuto, 2000). Thus, somatic mitochondria in several neuronal cell types buffer physiological calcium loads elicited by depolarization and/or action potentials (Thayer and Miller, 1990; Friel and Tsien, 1994; White and Reynolds, 1995; Herrington et al., 1996; Babcock et al., 1997). Under pathological conditions, e.g., excessive glutamate exposure, mitochondria of CNS neurons accumu-

\footnotetext{
Received July 15, 2002; revised Sept. 19, 2002; accepted Oct. 1, 2002.

This work was supported by the National Institutes of Health Intramural Research Program. We thank Drs. C. A. Brantner, R. D. Leapman, and T. S. Reese for resource support, helpful discussions, and technical assistance.

*N.B.P. and L.D.P.-M. contributed equally to this work.

Correspondence should be addressed to Brian Andrews, Building 36, Room 2A-21, Laboratory of Neurobiology, National Institute of Neurological Disorders and Stroke, National Institutes of Health, 36 Convent Drive, Bethesda, MD 20892 4062. E-mail: sba@helix.nih.gov.

Copyright (C) 2002 Society for Neuroscience 0270-6474/02/2210653-09\$15.00/0
}

strong $\mathrm{Ca}$ accumulation was reversible, because $[\mathrm{Ca}]_{\text {mito }}$ had recovered by $180 \mathrm{sec}$ after the tetanus. Ca sequestered within mitochondria was localized to small inclusions that were distributed heterogeneously within, and probably among, individual mitochondria. By $30 \mathrm{sec}$ after stimulation an active subpopulation of ER cisterns had accumulated more $\mathrm{Ca}$ than had mitochondria despite a $\sim 1$ sec delay before the onset of accumulation. Active ER cisterns retained their $\mathrm{Ca}$ load much longer ( $>3 \mathrm{~min}$ ) than mitochondria. The complementary time courses of mitochondrial versus $\mathrm{ER} \mathrm{Ca}^{2+}$ uptake and release suggest that these organelles participate in a choreographed interplay, each shaping dendritic $\mathrm{Ca}^{2+}$ signals within characteristic regimes of cytosolic $\mathrm{Ca}^{2+}$ concentration and time.

Key words: calcium; endoplasmic reticulum; mitochondria; hippocampus; synaptic activity; electron probe $x$-ray microanalysis

late large amounts of Ca (Budd and Nicholls, 1996; Stout et al., 1998; Brocard et al., 2001), ultimately leading to mitochondrial dysfunction and cell death (Reynolds, 1999; Nicholls and Budd, 2000).

Regarding synaptic $\mathrm{Ca}^{2+}$ transients, mitochondrial $\mathrm{Ca}^{2+}$ transport contributes to the regulation of $\left[\mathrm{Ca}^{2+}\right]_{\mathrm{i}}$ in presynaptic terminals during normal transmission (David et al., 1998; Peng, 1998) and post-tetanic potentiation [Tang and Zucker (1997), but see Zenisek and Matthews (2000)]. To date, however, the role of mitochondria in modulating spatiotemporal patterns of synaptically evoked postsynaptic $\mathrm{Ca}^{2+}$ transients, for example in dendrites of CNS pyramidal neurons, is unclear. Yet dendritic mitochondria are potentially of great importance because, given the subcellular architecture of dendrites, they are exposed to substantial $\left[\mathrm{Ca}^{2+}\right]_{\mathrm{i}}$ elevations after synaptic activity (Petrozzino et al., 1995; Helmchen et al., 1996).

In a previous study we found no elevation of mitochondrial total $\mathrm{Ca}$ concentration ([Ca $]_{\text {mito }}$ ) in hippocampal CA3 pyramidal dendrites at 3 min after synaptic stimulation, although a subset of ER contained large amounts of $\mathrm{Ca}$ at this and even later times (Pozzo-Miller et al., 1997). These results revealed a remarkably long persistence for ER Ca sequestration but did not address the subcellular distribution of $\mathrm{Ca}$ at times close to synaptically driven $\left[\mathrm{Ca}^{2+}\right]_{\mathrm{i}}$ transients, which peak and decay within seconds of synaptic stimulation (Regehr et al., 1989; Jaffe et al., 1992; Magee et al., 1995; Petrozzino et al., 1995; Spruston et al., 1995). We now have determined the distribution of $\mathrm{Ca}$ within the ER and mito- 
chondria of proximal CA3 dendrites at the peak of the free $\mathrm{Ca}^{2+}$ transient $(1 \mathrm{sec})$, just after its decay $(30 \mathrm{sec})$, and well after its return to prestimulus levels $(180 \mathrm{sec})$. A large rise and fall of $[\mathrm{Ca}]_{\text {mito }}$ was observed during the first minutes after synaptic activity in parallel with a delayed but sustained $\mathrm{Ca}$ accumulation in a subset of ER. These results indicate that in pyramidal dendrites both ER and mitochondria reversibly accumulate $\mathrm{Ca}$ but with characteristically different sequestration mechanisms and complementary temporal properties that are likely to be important in the modulation of dendritic $\mathrm{Ca}^{2+}$ signals.

\section{MATERIALS AND METHODS}

Stimulation and rapid freezing of organotypic hippocampal slice cultures. Slice cultures of hippocampus were prepared from postnatal day 7 rats in the manner of Stoppini et al. (1991). Such organotypic slice cultures are widely accepted experimental models (for review, see Gähwiler et al., 1997) and are essential for the present experiments because they provide healthy superficial neuronal cell bodies, dendrites, and synapses that are close enough to the surface to allow for rapid freezing with excellent structural preservation (Pozzo-Miller et al., 1993) and no elemental redistribution. The specific experimental setup is essentially similar to that described and schematically diagrammed in Pozzo-Miller et al. (1997), with one significant modification: two insulated nichrome wires (20 $\mu \mathrm{m}$ in diameter; California Fine Wire, Grover Beach, CA) for afferent fiber stimulation were attached permanently to custom-modified $12 \mathrm{~mm}$ Millicell-CM filter inserts (Millipore, Bedford, MA). The slice grew above one exposed uninsulated section of the wire that was fixed flush against the filter insert membrane, such that the wire ran under the dentate gyrus. The presence of the wires had no discernible effect on the growth, anatomy, or synaptic circuitry of the cultures. Just before a slice was transferred to a recording chamber, the exposed uninsulated section of the second wire was lowered onto the slice parallel to the lower wire, with a spacing of $\sim 1 \mathrm{~mm}$, and was fixed to the edge of the insert with silicone vacuum grease. The recording chamber was perfused continuously with oxygenated artificial CSF (aCSF) containing (in mM) 124 $\mathrm{NaCl}, 2 \mathrm{KCl}, 1.24 \mathrm{KH}_{2} \mathrm{PO}_{4}, 1.3 \mathrm{MgSO}_{4}, 17.6 \mathrm{NaHCO}_{3}, 2.5 \mathrm{CaCl}_{2}$, and 10 D-glucose; the solution was bubbled with $95 \% \quad \mathrm{O}_{2} / 5 \% \mathrm{CO}_{2}$. Field EPSPs (fEPSPs) were evoked at low frequency by single pulses (100 $\mu$ sec duration) delivered to the top wire by a multichannel stimulator and isolator set-up (Master-8 and ISO-Flex, AMPI, Jerusalem, Israel) and were recorded with a bridge amplifier (Axoclamp-1A, Foster City, CA), using an extracellular glass microelectrode filled with aCSF ( $2 \mathrm{M} \Omega$ final resistance) positioned in CA3 stratum lucidum. This arrangement was effective for generating fEPSPs along the apical CA3 dendritic field and permitted selection of the stimulus strength that was necessary to evoke subthreshold fEPSPs $(\sim 0.5 \mathrm{mV}$, without superimposed population spike) in each culture individually.

For slices with a $1 \mathrm{sec}$ interval between stimulation and freezing, cultures with the wires still in position were positioned briefly under a dissecting microscope to wick off adventitious surface fluid and to place (with a fine needle) three delicate copier toner marks that later would be used to triangulate the CA3 region in frozen specimens. Cultures then were mounted on custom-made freezing stages that adapted the Millicell-CM inserts to a custom-modified rapid freezing machine (LifeCell CF-100; The Woodlands, TX). These steps required $\sim 10 \mathrm{sec}$; in no case was the tissue touched or otherwise disturbed. The stimulator was used to trigger the freezing machine as well as the stimulus train, allowing rapid freezing at accurately programmable intervals as short as a few milliseconds between the delivery of a stimulus to mossy fibers and the instant of impact on the freezing block. The stimulus train used here, $50 \mathrm{~Hz} / 1 \mathrm{sec}$, is a standard high-frequency train and is identical to that described as the "single train" in previous work (Pozzo-Miller et al., 1997). For $30 \mathrm{sec}$ (and longer) experiments the interval is long enough that cultures can be stimulated alternatively in the recording chamber (and therefore can use cultures grown with or without embedded stimulating wires) and then mounted on stages and rapidly frozen. Experiments were performed to evaluate all permutations, and no differences were found among the various procedures. Controls, i.e., nonstimulated cultures, were subjected to all experimental manipulations except delivery of the tetanus. Again, no differences were observed between controls frozen directly from the recording chamber and those premounted on freezing stages.

Experiments were performed on slices $6-8 \mathrm{~d}$ in vitro. This relatively short time avoids one disadvantage of slice cultures, namely, that aberrant sprouting by intrinsic fibers may occupy vacant postsynaptic sites, leading to hyperexcitable slices. This isolation-induced sprouting becomes a significant problem only after 2 weeks in vitro (Pozzo-Miller et al., 1994).

Analytical electron microscopy. The principles and techniques for cryosectioning, electron microscopy, and electron probe x-ray microanalysis (EPMA) for measuring total (free plus bound) concentrations of diffusible elements at the subcellular level are well established (Kitazawa et al., 1983; Somlyo, 1985) (for review, see Roomans and Von Euler, 1996; Meldolesi and Grohovaz, 2001). Techniques for cryosectioning and EPMA within organelles of pyramidal neurons in slice cultures are described in Pozzo-Miller et al. (1997). Briefly, cryosections $(80 \mathrm{~nm}$ nominal thickness) were prepared from the well frozen specimen face by means of a Leica Ultracut S/FCS ultracryomicrotome (Deerfield, IL). Sections were mounted on carbon- and Formvar-coated grids and cryotransferred into an EM912 Omega electron microscope (LEO Electron Microscopy, Thornwood, NY) equipped with a Linksystem Pentafet energy-dispersive x-ray (EDX) detector (Oxford Instruments, Concord, MA) and a ProScan HSSC-1 slow-scan CCD camera $(1024 \times 1024)$ interfaced to AnalySIS software (Soft-Imaging Software GmbH, Munster, Germany). Sections were freeze dried in the microscope at approximately $-100^{\circ} \mathrm{C}$ and then recooled to approximately $-170^{\circ} \mathrm{C}$ for imaging and $\mathrm{x}$-ray analysis. Individual x-ray spectra were recorded for $100 \mathrm{sec}$ at $\sim 4 \mathrm{nA}$ probe current, using a focused probe with a diameter of $100 \mathrm{~nm}$ for mitochondria and cytoplasm and $\leq 50 \mathrm{~nm}$ for ER cisterns.

Spectra subsequently were processed and quantified using the program DeskTop Spectrum Analyzer (DTSA) for the Macintosh [C. E. Fiori, C. R. Swyt, R. L. Myklebust (1993) Office of Standard Reference Data, National Institute of Standards and Technology, Gaithersburg, MD]. A simplex fitting routine and the peak/continuum method (Kitazawa et al., 1983) were used to quantify the concentrations of the following elements in units of $\mathrm{mmol} / \mathrm{kg}$ dry weight: $\mathrm{Na}, \mathrm{Mg}, \mathrm{P}, \mathrm{Cl}, \mathrm{K}$, and $\mathrm{Ca}$. Methods for converting concentrations to $\mathrm{mmol} / \mathrm{kg}$ wet weight (the units for data presentation in Figs. 2B, 4) are described by Roomans and Von Euler (1996) and by Pozzo-Miller et al. (2000). Relative dry mass fractions required for this calculation were derived from x-ray continuum counts (Buchanan et al., 1993) specifically from these experiments. Mass fractions were $0.15 \pm 0.02,0.27 \pm 0.02$, and $0.45 \pm 0.03$ for cytoplasm, ER, and mitochondria, respectively; they were distributed normally and are consistent with published data (Pozzo-Miller et al., 1997, 2000). Throughout this work elemental symbols with the oxidation state specified, e.g., $\mathrm{Ca}^{2+}$, are used conventionally to indicate ions in the free, water-solvated state, whereas symbols without such specification, e.g., $\mathrm{Ca}$, refer to the element without regard to whether it is free or bound and are used mainly to indicate total concentrations as measured by EPMA.

Sampling, data analysis, and statistics. Individual x-ray spectra were recorded from the major $\mathrm{Ca}^{2+}$-regulating compartments of CA3 pyramidal dendrites, namely, cytoplasm, mitochondria, and ER. The term "ER" is used by convention throughout this paper to refer to structurally identified smooth-membrane cisterns and may include some elements that were not in fact a part of the true ER network, e.g., endocytic vesicles; this is, however, unlikely at the locations that were analyzed and would not affect materially any conclusions, as further discussed in Results. Measurements were performed at a distance of 50-100 $\mu \mathrm{m}$ from the cell soma and therefore were from unbranched primary dendrites, each arising from a different cell. Duplicate sampling, i.e., two dendrites from the same cell or two measurements from the same dendrite, was not likely. The afferent stimulation used here depolarizes most, but not all, CA3 neurons in a culture and most, but not all, dendrites of a given neuron. Because the aim of the present experiments was to compare $\mathrm{Ca}^{2+}$ buffering in various dendritic compartments after $\mathrm{Ca}^{2+}$ influx, dendrites that did not respond to the stimulus train [that is, dendrites that did not show the characteristic elemental changes known to accompany dendritic depolarization and $\mathrm{Ca}^{2+}$ influx and in which the elemental composition of all compartments was statistically (ANOVA) indistinguishable from controls] were excluded from the data set. Typically, the fraction of dendrites that was excluded was small, $\sim 10 \%$.

Our sampling strategy aimed to acquire five analyses per dendrite for each compartment from five different stimulated dendrites per culture. In practice, the actual number of analyses per section varied because of an abundance or paucity of organelles or dendrites but in no case was fewer than three compartments or dendrites. The final data set was unbalanced and was treated as such for statistical analysis. Nested ANOVA indicated that in all cases there were no differences between slice cultures from the 
Table 1. Elemental concentrations in dendritic compartments of hippocampal CA3 pyramidal neurons after synaptic activity

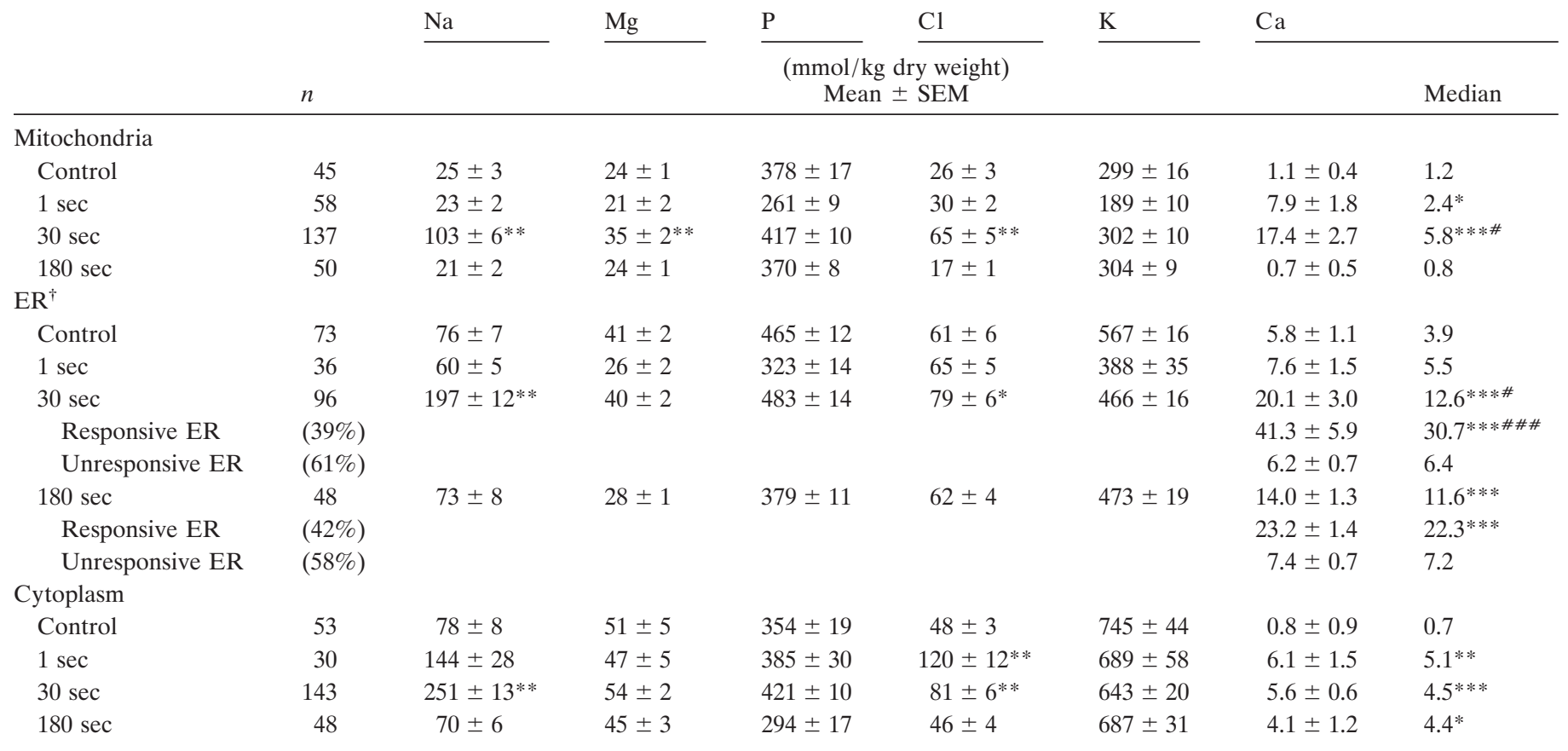

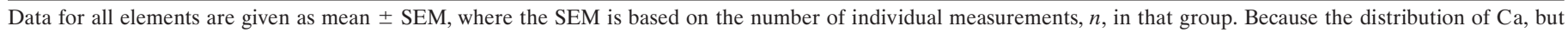
not other elements, in most compartments after stimulation is not normal (Kolmogorov-Smirnov test), Ca concentrations also are given as medians.

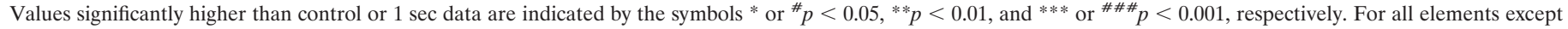

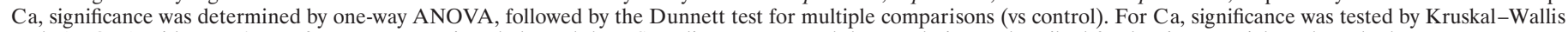
rank ANOVA with Dunn's test for nonparametric unbalanced data. Sampling strategy and data analysis are described further in Materials and Methods.

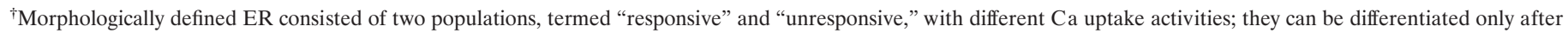
ER Ca accumulation (see also Pozzo-Miller et al., 1997).

same experimental group; therefore, data from individual cultures (control, $n=4 ; 1 \mathrm{sec}, n=3 ; 30 \mathrm{sec}, n=5 ; 180 \mathrm{sec}, n=3)$ were pooled to calculate group means and medians. For all elements except Ca, statistical differences among experimental groups were determined using one-way ANOVA, followed by the Dunnett's test for multiple comparisons (vs controls). Because much of the critical data for $\mathrm{Ca}$ was not distributed normally, as determined by the Kolmogorov-Smirnov normality test, $\mathrm{Ca}$ concentrations are given as both means and medians in Table 1. Similarly, and for the sake of clarity, convenience, and consistency, $\mathrm{Ca}$ concentrations are presented throughout the text as both means and medians. However, $\mathrm{Ca}$ data in all figures are medians. Statistical differences between $\mathrm{Ca}$ concentrations in various experimental groups were determined using the Kruskal-Wallis nonparametric ANOVA with Dunn's test for multiple comparisons of unbalanced data. Analysis was performed by means of InStat software (GraphPad Software, San Diego, CA).

\section{RESULTS}

\section{Afferent synaptic stimulation evokes calcium uptake by dendritic mitochondria}

CA3 pyramidal neurons in hippocampal slice cultures respond to high-frequency stimulation of afferent mossy fibers with micromolar elevations in dendritic $\left[\mathrm{Ca}^{2+}\right]_{\mathrm{i}}$ that reach a maximum in $\sim 1 \mathrm{sec}$ and decay to baseline in $<20 \mathrm{sec}$ (Pozzo-Miller et al., 1993; Petrozzino et al., 1995). To investigate correlated changes in the concentration and distribution of intracellular total $\mathrm{Ca}$, we rapidly froze slice cultures at 1 or $30 \mathrm{sec}$ after a single $1 \mathrm{sec} / 50 \mathrm{~Hz}$ tetanus. This afferent stimulation, identical to the "single train" stimulus used in previous studies (Pozzo-Miller et al., 1997), depolarizes most of the dendrites on most of the CA3 neurons in slice culture (for acute slice experiments, see Jaffe et al., 1992; Magee et al., 1995; Spruston et al., 1995; Johnston et al., 1996;
Helmchen, 1999). Subsequently, concentrations of total $\mathrm{Ca}$, as well as $\mathrm{Na}, \mathrm{Mg}, \mathrm{P}, \mathrm{Cl}$, and $\mathrm{K}$ within the three principal subcellular compartments of CA3 proximal apical dendrites, namely, mitochondria, ER, and cytoplasm (Fig. 1), were measured by EPMA of freeze-dried cryosections prepared from frozen slice cultures. Because the aim of the present experiments was to characterize the $\mathrm{Ca}^{2+}$ buffering behavior of the various dendritic compartments after $\mathrm{Ca}^{2+}$ influx, measurements were performed only in those dendrites that responded to the stimulus train as indicated by the characteristic elemental changes known to accompany depolarization-induced $\mathrm{Ca}^{2+}$ influx.

The results revealed a rapid, graded, and reversible elevation in the total $\mathrm{Ca}$ concentration within dendritic mitochondria $\left([\mathrm{Ca}]_{\text {mito }}\right)$. Afferent tetanic stimulation induced a significant elevation of $[\mathrm{Ca}]_{\text {mito }}$ at both $1 \mathrm{sec}$ [to $7.9 \mathrm{mmol} / \mathrm{kg}$ dry weight (mean); $2.4 \mathrm{mmol} / \mathrm{kg}$ (median)] and $30 \mathrm{sec}$ [to $17.4 \mathrm{mmol} / \mathrm{kg}$ (mean); $5.8 \mathrm{mmol} / \mathrm{kg}$ (median)] after synaptic activation, compared with the characteristically low $[\mathrm{Ca}]_{\text {mito }}[1.1 \mathrm{mmol} / \mathrm{kg}$ (mean); $1.2 \mathrm{mmol} / \mathrm{kg}$ (median)] in dendrites of control cultures that were grown, mounted, and frozen identically but received only low-frequency test stimuli (Table 1; Fig. $2 A$, right panel). (Because measurements of $\mathrm{Ca}$ concentrations were not distributed normally under conditions of $\mathrm{Ca}^{2+}$ uptake, as discussed below, $\mathrm{Ca}$ concentrations are given throughout the text as both means and medians; see Materials and Methods for details.) As an indication of how robust mitochondrial $\mathrm{Ca}$ accumulation could be, individual local measurements of $[\mathrm{Ca}]_{\text {mito }}$ ranged as high as $60.0 \mathrm{mmol} / \mathrm{kg}$ at $1 \mathrm{sec}$ and $220 \mathrm{mmol} / \mathrm{kg}$ at $30 \mathrm{sec}$. To place these observations in a biochemical perspective, the mean concentra- 
Figure 1. Ultrastructural organization of proximal dendrites in CA3 hippocampal neurons. Shown are representative digital transmission electron micrographs of freeze-dried cryosections prepared from rapidly frozen hippocampal slice cultures, illustrating the subcellular structure of proximal dendritic compartments and demonstrating that the three compartments targeted for EPMA (ER, mitochondria, and cytoplasm) are readily identifiable. Images were recorded using standard low-dose techniques in a LEO 912 Omega cryoanalytical electron microscope at $-170^{\circ} \mathrm{C}$ by means of a ProScan slow-scan CCD camera $(1024 \times 1024)$. Survey view $(A)$ shows the general appearance of the proximal dendritic field of CA3 neuropil in unstained cryosections from slice cultures. Three primary dendrites (asterisks) course across the field; cytoplasm, characterized by longitudinal bundles of microtubules, and elongated mitochondria (adjacent to asterisks) are evident. At higher magnification $(B)$ both mitochondria and ER [essentially the only intracellular organelles present in proximal apical dendrites at the distance that was sampled $(50-100 \mu \mathrm{m}$ from the soma)] are apparent. The latter is seen as a network of smooth-surfaced cisterns, often in clusters (arrowheads). Together, the ER, mitochondria, and cytosol comprise essentially all of the dendritic volume while also including all important components of the $\mathrm{Ca}^{2+}$ regulatory system. Scale bars, $1 \mu \mathrm{m}$.
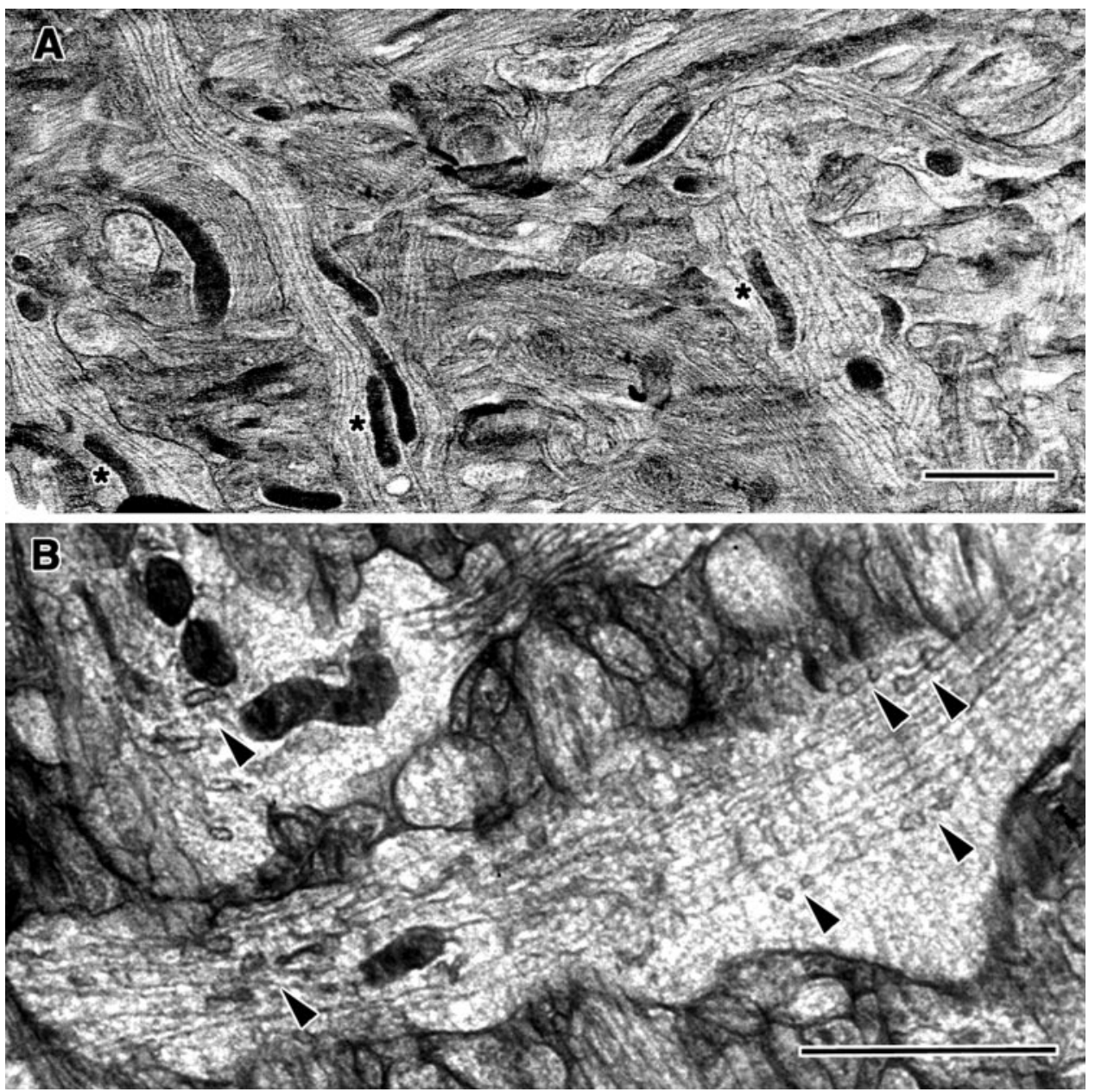

tions given above are equivalent (assuming that mitochondria are $75 \%$ protein by weight) to increases from resting levels of $\sim 1.5$ $\mathrm{nmol} / \mathrm{mg}$ protein to $\sim 10.5$ and $\sim 23.2 \mathrm{nmol} / \mathrm{mg}$ protein, respectively. This elevation of mitochondrial $\mathrm{Ca}$ is transient, as indicated by the finding, consistent with previous observations (Pozzo-Miller et al., 1997) that under identical conditions $[\mathrm{Ca}]_{\text {mito }}$ had recovered completely 3 min after stimulation.

Among other intracellular elements, only sodium was elevated dramatically as a result of the afferent tetanus. Total Na elevations occurred not just in mitochondria but in all three dendritic compartments and were especially large at $30 \mathrm{sec}$ (Table 1). Comparable changes previously were observed in CA3 dendrites in the same preparation after strong stimulation with four successive tetani and were attributed to the expected enhanced activity of $\mathrm{Na}^{+}$channels and $\mathrm{Na}^{+} / \mathrm{Ca}^{2+}$ exchangers (PozzoMiller et al., 1997). Stimulus-induced $\mathrm{Cl}$ increases also were detected; as expected, these were smaller and appeared to progress sequentially from cytosol to mitochondria, consistent with counter-ion flow through the cell. Like $\mathrm{Ca}$, the $\mathrm{Na}$ and $\mathrm{Cl}$ elevations were completely reversible, returning to prestimulus levels in all compartments by 3 min after the tetanus (Table 1).

\section{Calcium sequestration in dendritic ER is slower than in mitochondria but persists longer}

The ER of responsive dendrites (as described in the previous section) also exhibited elevated levels of total $\mathrm{Ca}\left([\mathrm{Ca}]_{\mathrm{ER}}\right)$ at 30 sec after stimulation, but, in contrast to mitochondria, not at $1 \mathrm{sec}$ (Table 1; Fig. $2 A$, middle panel). $[\mathrm{Ca}]_{\mathrm{ER}}$ was elevated only in a responsive subset of ER cisterns, defined as those in which $[\mathrm{Ca}]_{\mathrm{ER}}$ exceeded $15 \mathrm{mmol} / \mathrm{kg}$ dry weight. This population, $\sim 40 \%$ of analyzed cisterns with a mean $[\mathrm{Ca}]_{\mathrm{ER}}$ of $41.3 \mathrm{mmol} / \mathrm{kg}$ dry weight (median, $30.7 \mathrm{mmol} / \mathrm{kg}$ ), was qualitatively and quantitatively similar to the subset of Ca-sequestering ER previously characterized in these slice cultures (Pozzo-Miller et al., 1997). The remaining $\sim 60 \%$ of smooth membrane elements within the same responsive dendrites evidently do not accumulate $\mathrm{Ca}$, because they belong to a normally distributed population with a mean $[\mathrm{Ca}]_{\mathrm{ER}}$ of $\sim 6 \mathrm{mmol} / \mathrm{kg}$, statistically indistinguishable from control ER (Table 1). These cisterns are very likely also elements of the true endoplasmic reticulum, because other smoothmembraned cisterns or vesicles are quite rare at the sampled level of primary hippocampal dendrites. We note that if the nonaccumulating ER pool were contaminated adventitiously by non-ER elements, this would have the effect of deflating the estimate of the responsive ER fraction but would not affect quantitative comparisons of $\mathrm{Ca}$ accumulation between organelles.

At 3 min after stimulation [Ca $]_{\mathrm{ER}}$ was still elevated (Table 1; Fig. $2 A$, middle panel), indicating that $\mathrm{Ca}^{2+}$ uptake by the ER continued, or was at least sustained (depending on the magnitude and rate of $\mathrm{Ca}^{2+}$ release from ER), for several minutes beyond the termination of $\mathrm{Ca}^{2+}$ entry. The ratio of responsive/nonresponsive cisterns essentially was unchanged, arguing against late recruitment to the responsive pool.

The fractional water and dry mass contents of mitochondria, ER, and cytoplasm differ substantially. Consequently, to compare 

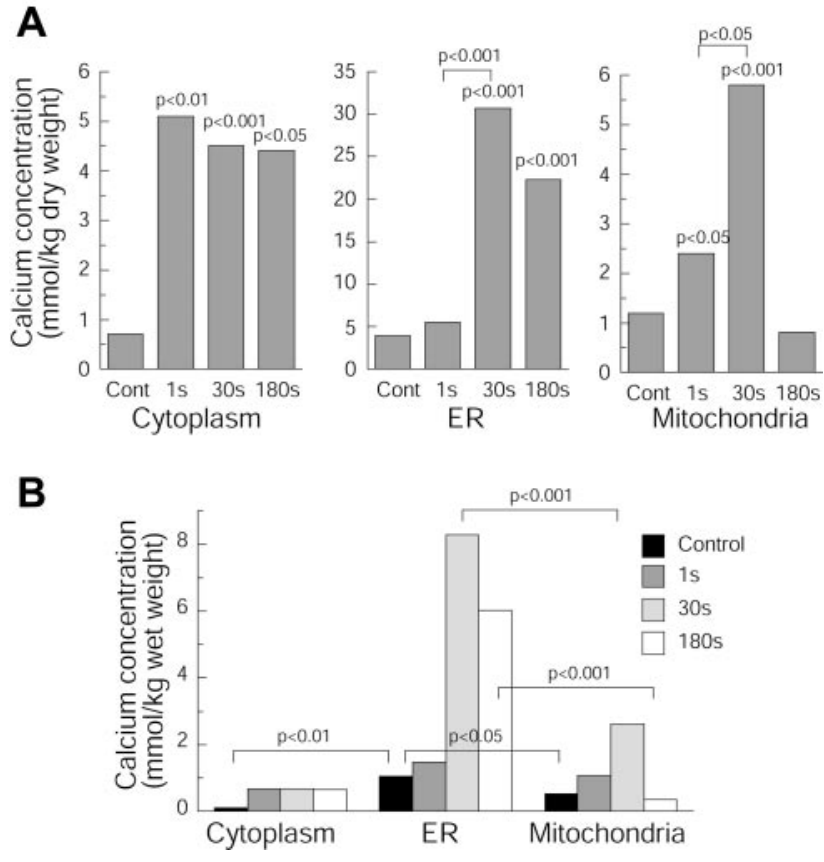

Figure 2. Calcium accumulation in dendritic compartments of CA3 hippocampal neurons. Comparison of calcium concentrations at different time points after synaptic stimulation in three dendritic compartments. In certain instances data were not distributed normally; therefore, all results are given as medians. In $A$, data are in primary units of $\mathrm{mmol} / \mathrm{kg}$ dry weight. In $B, \mathrm{Ca}$ concentrations have been converted to $\mathrm{mmol} / \mathrm{kg}$ wet weight (as described in Materials and Methods) to facilitate quantitative comparisons of $\mathrm{Ca}$ concentrations between compartments. Uncertainties introduced by this conversion are discussed in Results. Statistical significance ( $p$ values) relative to corresponding resting $\mathrm{Ca}$ concentrations is given above the bars; other significant differences are indicated by bracketed pairs. Statistical tests are described in Materials and Methods. A, At $1 \mathrm{sec}$ after afferent synaptic stimulation $[\mathrm{Ca}]_{\text {mito }}$ and $[\mathrm{Ca}]_{\mathrm{cyto}}$, but not $[\mathrm{Ca}]_{\mathrm{ER}}$, were elevated compared with resting levels. By $30 \mathrm{sec}$ after stimulation $\mathrm{Ca}$ concentrations were elevated in all three compartments. (For ER, only data from the subpopulation that actively sequesters $\mathrm{Ca}$ in responsive dendrites, as presented in Table 1 and discussed in Results, are included.) By $180 \mathrm{sec}$ after stimulation only [Ca $]_{\text {mito }}$ had recovered. Note the different $y$-axes. $B$, At rest, ER Ca levels are significantly higher than those in mitochondria and cytosol (compare black bars). The ER also contains by far the highest Ca concentrations at 30 and $180 \mathrm{sec}$ (compare light gray and white bars), but not at $1 \mathrm{sec}$ (dark gray bars).

the distribution of $\mathrm{Ca}$ between compartments, it is necessary to convert EPMA-derived $\mathrm{Ca}$ concentrations to hydrationcompensated units such as $\mathrm{mmol} / \mathrm{kg}$ wet weight (which is also approximately equivalent to $\mathrm{mmol} / \mathrm{l}$ hydrated cell volume). Median data in Figure $2 B$ have been converted as described in Materials and Methods. Although this conversion inevitably introduces additional uncertainties attributable, for example, to errors in the estimation of dry mass fractions for each compartment, it serves to factor out the effects of compartmental mass differences so as to convey a realistic sense of the quantitative differences in the amounts of sequestered $\mathrm{Ca}$ in different organelles. $[\mathrm{Ca}]_{\mathrm{ER}}$ in control slices was much higher on a wetweight basis than $[\mathrm{Ca}]_{\text {mito }}$ or cytoplasmic total $\mathrm{Ca}\left([\mathrm{Ca}]_{\text {cyto }}\right)$ (Fig. $2 B)$, indicating that under basal conditions the ER is the most powerful $\mathrm{Ca}^{2+}$ buffer. This observation is also consistent with a role for dendritic ER as a releasable $\mathrm{Ca}^{2+}$ store (SeymourLaurent and Barish, 1995; Pozzo-Miller et al., 1996; Garaschuk et al., 1997; Emptage et al., 1999; Nakamura et al., 1999; Rae et al., 2000). At $30 \mathrm{sec}$ after tetanic stimulation, when both ER and mitochondria are accumulating $\mathrm{Ca}$ avidly, $[\mathrm{Ca}]_{\mathrm{ER}}$ is substantially larger than $[\mathrm{Ca}]_{\text {mito }}$ (Fig. $2 B$ ). The difference is even greater at 3 min after stimulation, at which time $[\mathrm{Ca}]_{\mathrm{ER}}$ is still elevated significantly, but $[\mathrm{Ca}]_{\text {mito }}$ has recovered completely. $[\mathrm{Ca}]_{\mathrm{ER}}$ was not significantly different from the control at $1 \mathrm{sec}$ post-tetanus, indicating a delay of at least $1 \mathrm{sec}$ before net $\mathrm{ER} \mathrm{Ca}^{2+}$ uptake begins.

$[\mathrm{Ca}]_{\text {cyto }}$ in CA3 dendrites was elevated maximally within $1 \mathrm{sec}$ of stimulation (Table 1; Fig. 2A, left panel). Although the absolute increase in the cytoplasmic $\mathrm{Ca}$ concentration is modest, $\sim 5$ $\mathrm{mmol} / \mathrm{kg}$ dry weight, and much less than in ER or mitochondria, the cytoplasmic volume fraction is correspondingly larger than that of either organelle. Dendritic cytoplasm thus represents a significant $\mathrm{Ca}^{2+}$-binding reservoir, approximately equivalent by amount to organelle sequestration (see also Pozzo-Miller et al., 2000).

\section{Spatial heterogeneity of synaptically evoked mitochondrial Ca uptake}

The values of $[\mathrm{Ca}]_{\text {mito }}$ presented in Table 1 and Figure 2 are means or medians of measurements obtained with randomly placed probes (diameter, $\sim 100 \mathrm{~nm}$ ) in each mitochondria in a given dendrite and therefore represent spatially averaged concentrations. (A similar approach with $\sim 50 \mathrm{~nm}$ diameter probes was used for measurements of $[\mathrm{Ca}]_{\mathrm{ER}}$.) This sampling strategy provides a reasonable estimate of spatially averaged $[\mathrm{Ca}]_{\text {mito }}$ at the level of individual dendrites, although sequestered $\mathrm{Ca}$ is not distributed uniformly within, and perhaps among, individual mitochondria. Under resting conditions individual measurements of $[\mathrm{Ca}]_{\text {mito }}$ were always low; as expected for brain mitochondria (Somlyo et al., 1985; Andrews et al., 1988). The distribution of these measurements is normal (Fig. $3 A$, top), with a tight dispersion consistent with that expected from statistical errors of EPMA analysis. After afferent fiber stimulation this distribution became skewed toward higher $[\mathrm{Ca}]_{\text {mito }}$ by the emergence of a fraction of measurements with elevated $[\mathrm{Ca}]_{\text {mito }}$ (Fig. $3 \mathrm{~A}$, middle, bottom). The most extreme members of this subset had exceedingly high $[\mathrm{Ca}]_{\text {mito }}$, often $>100 \mathrm{mmol} / \mathrm{kg}$ dry weight.

The skewed distribution of $[\mathrm{Ca}]_{\text {mito }}$ after stimulation arises at least partly from spatial heterogeneity of accumulated $\mathrm{Ca}$ within individual mitochondria, as reflected in the widely dispersed values for single measurements within the same mitochondrion (Fig. 3B). The basis for this form of spatial heterogeneity lies in the chemical nature of mitochondrial $\mathrm{Ca}$ sequestration. We and others have reported evidence for the formation, in intact stimulated neurons, of discrete calcium- and phosphorus-rich complexes that are thought to reflect a reversible, high-capacity $\mathrm{Ca}$ storage mechanism (David, 1999; Pivovarova et al., 1999). In frog sympathetic neurons depolarized with high $\mathrm{K}^{+}$such complexes appear as one or more small $(\sim 10 \mathrm{~nm})$ punctate inclusions within the mitochondrial matrix. A similar mechanism of mitochondrial $\mathrm{Ca}$ sequestration in CA3 dendrites would account for the frequency distributions of $[\mathrm{Ca}]_{\text {mito }}$ observed here (Fig. $3 A$ ), in that some fraction of $\mathrm{Ca}$-accumulating mitochondria nonetheless are expected to give low individual measurements of $[\mathrm{Ca}]_{\text {mito }}$ because the local sites of $\mathrm{Ca}$ sequestration were missed by randomly placed probes. An additional level of heterogeneity, caused by variability among mitochondria, is also plausible and perhaps likely (see Discussion). 


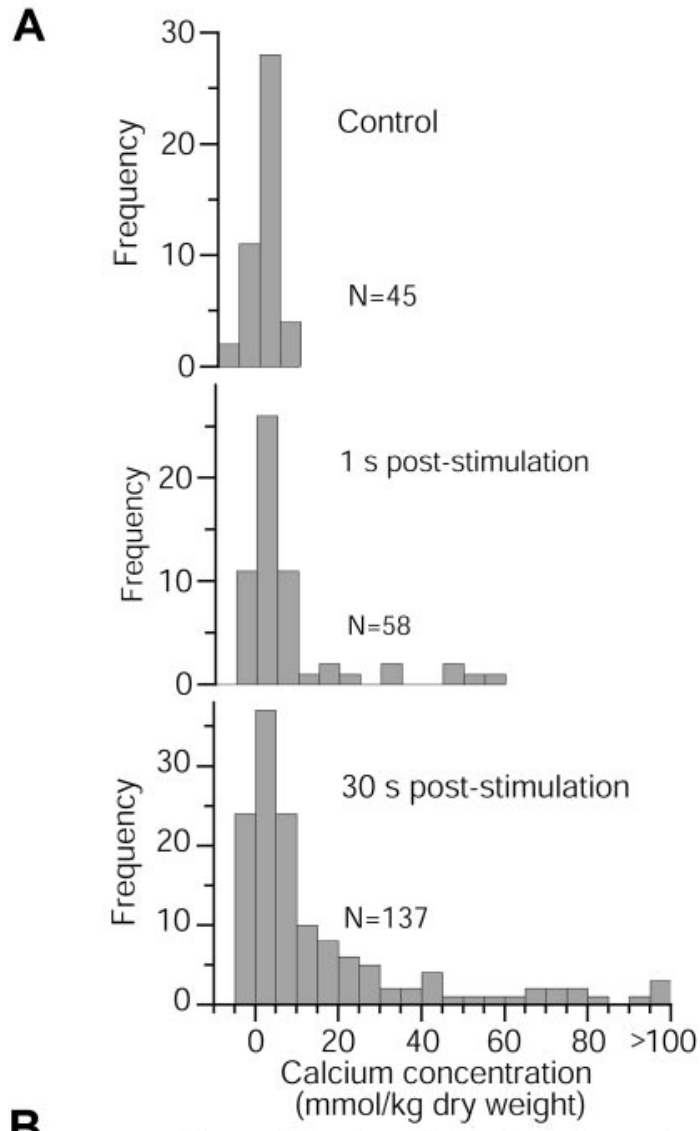

B

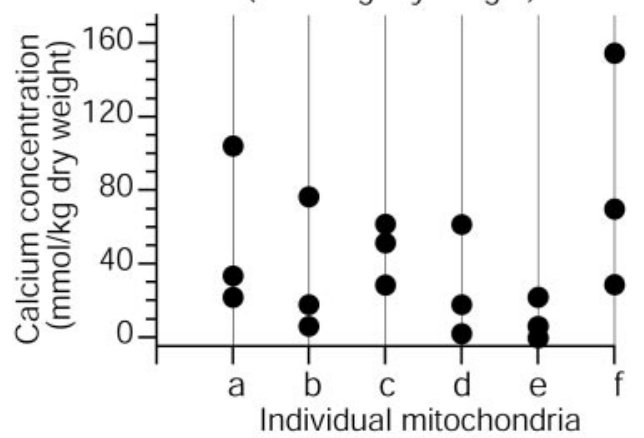

Figure 3. Heterogeneous distribution of $[\mathrm{Ca}]_{\text {mito }}$ within individual mitochondria after synaptic stimulation. $A$, Mean $[\mathrm{Ca}]_{\text {mito }}$ in resting dendrites is low, and the distribution of individual measurements is normal (top panel), as indicated by a good fit $\left(R^{2}=0.99\right)$ to a single Gaussian with a width $(\sigma=2.5 \mathrm{mmol} / \mathrm{kg}$ dry weight $)$ expected because of statistical uncertainties in EDX analysis. At $1 \mathrm{sec}$ (middle panel) and $30 \mathrm{sec}$ (bottom panel) the distribution becomes progressively skewed toward higher $[\mathrm{Ca}]_{\text {mito }}$ as a result of a sequestration mechanism that concentrates $\mathrm{Ca}$ in small inclusions within the mitochondrial matrix. $B$, Distribution of single $[\mathrm{Ca}]_{\text {mito }}$ measurements from six representative mitochondria with elevated $\mathrm{Ca}$ levels that were analyzed at three separate locations using a $100 \mathrm{~nm}$ probe. Large differences in $[\mathrm{Ca}]_{\text {mito }}$ within each of these mitochondria reflect the heterogeneous distribution of calcium within individual mitochondria.

\section{DISCUSSION}

Mitochondria in a wide variety of cell types, including central pyramidal neurons (White and Reynolds, 1995; Wang and Thayer, 1996), accumulate $\mathrm{Ca}^{2+}$ after micromolar elevations in $\left[\mathrm{Ca}^{2+}\right]_{\mathrm{i}}$ (Pozzan and Rizzuto, 2000), but a significant role for dendritic mitochondrial $\mathrm{Ca}^{2+}$ uptake after synaptic activityinduced $\mathrm{Ca}^{2+}$ elevations has not been demonstrated. Most avail- able data on mitochondrial $\mathrm{Ca}^{2+}$ transport in neurons come from somatic measurements and are therefore of uncertain relevance to dendritic $\mathrm{Ca}^{2+}$ signaling. The present experiments show that mitochondria in proximal dendrites of CA3 pyramidal neurons rapidly and transiently accumulate large amounts of $\mathrm{Ca}$ in the seconds after afferent fiber stimulation. Presumably, rapid $\mathrm{Ca}^{2+}$ uptake occurs because dendritic $\left[\mathrm{Ca}^{2+}\right]_{i}$ reaches the supramicromolar levels (Petrozzino et al., 1995) consistent with strong activation of the mitochondrial uniporter (for isolated cardiac and liver mitochondria, $\mathrm{EC}_{50} \sim 10-20 \mu \mathrm{M}$; Gunter and Pfeiffer, 1990) and possibly the mitochondrial rapid uptake mode (RaM; Gunter et al., 2000). The $\mathrm{Ca}^{2+}$ uptake rate for dendritic mitochondria over the first second after synaptic stimulation is $9.0 \pm 2.9 \mathrm{nmol} / \mathrm{mg}$ protein/sec (estimated from data in Table 1 as the difference between $[\mathrm{Ca}]_{\text {mito }}$ at $1 \mathrm{sec}$ and at rest). This value compares reasonably with the maximal velocity of the uniporter in isolated mitochondria (10-30 nmol/mg protein/sec; Gunter and Pfeiffer, 1990) as well as with $\mathrm{Ca}^{2+}$ uptake rates estimated in mitochondria of chromaffin cells (Babcock et al., 1997) and sympathetic neurons (Pivovarova et al., 1999). The large amounts of mitochondrially sequestered Ca found here are also consistent with data from physiologically stimulated nonexcitable cells (Montero et al., 2000).

Dendritic mitochondria still retain a significant $\mathrm{Ca}$ load $30 \mathrm{sec}$ after stimulation (Fig. 2), well after $\left[\mathrm{Ca}^{2+}\right]_{i}$ essentially has returned to prestimulus levels. By this time the net uptake rate has fallen dramatically, which is explained by the decreasing velocity of $\mathrm{Ca}^{2+}$ uptake as $\left[\mathrm{Ca}^{2+}\right]_{\mathrm{i}}$ declines and by the activation of mitochondrial $\mathrm{Ca}^{2+}$ extrusion mechanisms. The synaptically induced rise in $[\mathrm{Ca}]_{\text {mito }}$ is completely reversible, as indicated by the observation that $[\mathrm{Ca}]_{\text {mito }}$ has recovered to prestimulus levels 3 min after afferent stimulation (see also Pozzo-Miller et al., 1997). This implies a $\mathrm{Ca}^{2+}$ recovery half-time of $1-2 \mathrm{~min}$, which is compatible with measured $\mathrm{Ca}^{2+}$ extrusion rates in other neuronal mitochondria (Colegrove et al., 2000) and also consistent with $\mathrm{Ca}^{2+}$ extrusion mainly via the $\mathrm{Na}^{+} / \mathrm{Ca}^{2+}$ exchanger, the activity of which would, in turn, account for the elevated levels of mitochondrial $\mathrm{Na}^{+}$found here. Last, mitochondrial $\mathrm{Ca}^{2+}$ uptake after a single tetanic stimulus is consistent with similarly evoked changes in the mitochondria membrane potential in pyramidal dendrites (Bindokas et al., 1998), changes that presumably reflect mitochondrial $\mathrm{Ca}$ accumulation.

It should be mentioned that the dynamic pattern of elemental changes described here, namely, sequential or parallel elevation and recovery of cytoplasmic and organelle $\mathrm{Ca}$ and $\mathrm{Na}$, has been observed in other neuronal systems, for example in the somata of cerebellar granule cells (Kiedrowski et al., 1994) and sympathetic neurons (Pivovarova et al., 1999) after strong $\mathrm{K}^{+}$depolarization, and appears to be a characteristic, physiologically normal consequence of $\mathrm{Ca}^{2+}$ entry and/or clearance mechanisms. In contrast to injurious stimuli, e.g., anoxia (Taylor et al., 1999) or high concentrations of glutamate (Kiedrowski et al., 1994), which evoke very large elevations of cytoplasmic $\mathrm{Ca}$ and $\mathrm{Na}$, tetanusevoked elevations of these elements are much smaller and completely reversible (Table 1) (Pozzo-Miller et al., 1997) and can be triggered repeatedly and reproducibly. Accumulating evidence suggests that $\mathrm{Na}^{+}$spikes or transients in pyramidal dendrites may subserve important functions such as triggering $\mathrm{Ca}^{2+}$ entry (Jaffe et al., 1992; Spruston et al., 1995; Johnston et al., 1996) or even acting as an independent signaling pathway (Callaway and Ross, 1997; Rose and Konnerth, 2001). Similarly, large cytosolic $\mathrm{Na}^{+}$ elevations appear to be an important component of transmitter release mechanisms in presynaptic terminals (Zhong et al., 2001). 
So far we have evaluated mitochondrial $\mathrm{Ca}^{2+}$ uptake on the basis of averaged measurements of $[\mathrm{Ca}]_{\text {mito }}$ at random locations within individual mitochondria, but this approach is oversimplified because the actual spatial distribution of accumulated $\mathrm{Ca}$ is clearly heterogeneous. One major factor underlying this heterogeneity is the punctate distribution of sequestered $\mathrm{Ca}$ within the matrix of individual mitochondria. This distribution is a reflection of a major mechanism of $\mathrm{Ca}^{2+}$ buffering and sequestration that, as described above (Fig. 3), gives a skewed distribution of individual measurements of $[\mathrm{Ca}]_{\text {mito }}$. This occurrence obscures higher levels of heterogeneity such as intermitochondrial variations that might reflect variability in mitochondrial energetics (Buckman and Reynolds, 2001) or spatial distribution (Collins et al., 2002) or in local $\left[\mathrm{Ca}^{2+}\right]_{\mathrm{i}}$ levels. In sympathetic neurons (Pivovarova et al., 1999), as well as in other excitable and nonexcitable cells (Montero et al., 2000; Collins et al., 2002), there is evidence for differences in $\mathrm{Ca}^{2+}$ uptake between individual mitochondria responding to the same stimulus in the same cell. These differences appear to depend at least partly on proximity to a local $\mathrm{Ca}^{2+}$ source. For mitochondria in dendrites of pyramidal neurons a similar heterogeneous response would be consistent with the skewed $[\mathrm{Ca}]_{\text {mito }}$ distribution, but evidence that this occurs is masked because the intramitochondrial Ca-rich inclusions affect the frequency distributions in the same way as would intermitochondrial heterogeneity. If, in fact, there are differences in $[\mathrm{Ca}]_{\text {mito }}$ between mitochondria, this well may reflect proximity to $\mathrm{Ca}^{2+}$ channels of the dendritic plasma membrane, a situation for which there is evidence in sympathetic neurons (Pivovarova et al., 1999) and secretory cells (Tse et al., 1997). Spatially resolved $[\mathrm{Ca}]_{\text {mito }}$ measurements, i.e., "calcium maps" (Meldolesi and Grohovaz, 2001), will be necessary to address this issue.

Present results confirm and extend our previous observation that, within dendrites that have responded to synaptic stimulation with an increase in $\left[\mathrm{Ca}^{2+}\right]_{i}$, a specific subset of ER has a profound capacity for accumulating and storing calcium. Figure 4 compares the magnitude and time courses of mitochondrial and ER $\mathrm{Ca}^{2+}$ uptake and release. It illustrates the fact that, in both dendritic organelles, the evoked Ca load persists well after decay of the $\mathrm{Ca}^{2+}$ transient, but the ER Ca load is particularly longlived; previously published observations (Pozzo-Miller et al., 1997) indicate that Ca-accumulating ER may sustain their $\mathrm{Ca}$ load for longer than $15 \mathrm{~min}$. Another interesting new finding is that $\mathrm{ER} \mathrm{Ca}^{2+}$ uptake appears to be delayed for at least $1 \mathrm{sec}$ relative to the cytosolic $\mathrm{Ca}^{2+}$ transient and to the onset of mitochondrial $\mathrm{Ca}^{2+}$ uptake. This may reflect the relative $\mathrm{Ca}^{2+}$ dependencies of the uptake mechanisms, i.e., the uniporter and RaM versus sarcoplasmic/endoplasmic reticulum $\mathrm{Ca}^{2+}$-ATPase (SERCA) pumps in the ER. Alternatively, it may indicate release from $\mathrm{Ca}$ stores, which is known to be evoked in CA3 pyramidal neurons by mossy fiber activation (Pozzo-Miller et al., 1996; Yeckel et al., 1999). The role of releasable stores in dendritic $\mathrm{Ca}^{2+}$ signaling is an area of active investigation. Several recent studies indicate that $\mathrm{Ca}^{2+}$ release from ryanodine-sensitive and/or $\mathrm{IP}_{3}$-sensitive internal stores may be a significant mechanism for signal amplification and/or modulation in both dendrites and spines of hippocampal neurons (Seymour-Laurent and Barish, 1995; Pozzo-Miller et al., 1996; Garaschuk et al., 1997; Emptage et al., 1999; Nakamura et al., 1999, 2000; Yeckel et al., 1999; Rae et al., 2000; Kapur et al., 2001). In the present case, because the ER reloads and even overloads during later stages of net $\mathrm{Ca}$ accumulation, dendritic ER may act first as a $\mathrm{Ca}^{2+}$ source to amplify the original $\mathrm{Ca}^{2+}$ signal and later switch into a buffering

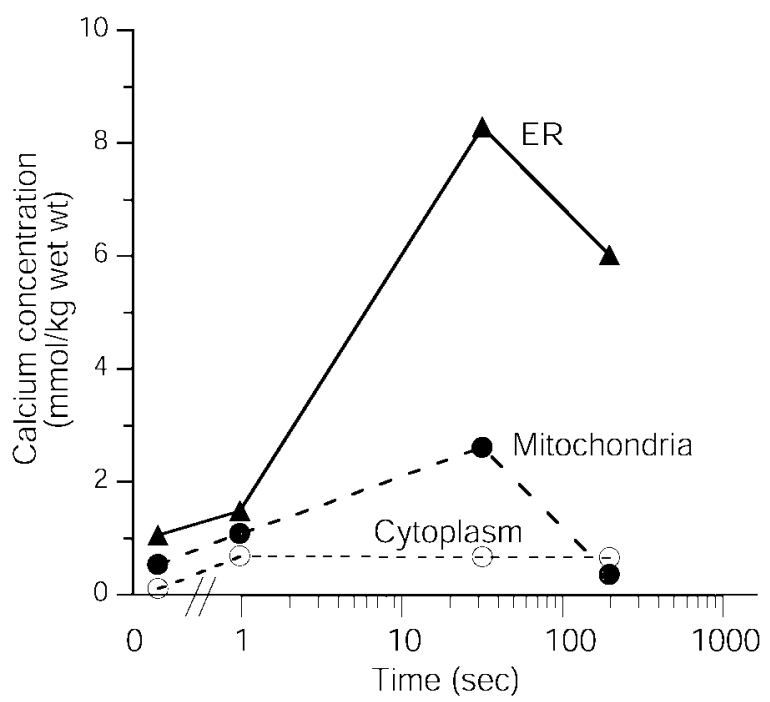

Figure 4. Calcium dynamics in dendritic compartments after synaptic stimulation. Time courses for $[\mathrm{Ca}]_{\text {cyto }}$ (open circles), $[\mathrm{Ca}]_{\text {mito }}$ ( filled circles), and $[\mathrm{Ca}]_{\mathrm{ER}}$ ( filled triangles; responsive subset only at 30 and $180 \mathrm{sec}$ ) illustrate complementary temporal relationship for activity-dependent $\mathrm{Ca}^{2+}$ uptake and release by dendritic mitochondria and ER. These organelles appear to transport $\mathrm{Ca}^{2+}$ within distinct, possibly cooperative, time domains. For example, $[\mathrm{Ca}]_{\text {mito }}$ increases earlier and declines faster than $[\mathrm{Ca}]_{\mathrm{ER}}$, which remained elevated for $>10 \mathrm{~min}$. Data are given as medians. Note the log scale on the abscissa.

mode. We have demonstrated recently such a switchover in the caffeine/ryanodine-sensitive Ca stores of sympathetic neurons (Albrecht et al., 2001; Hongpaisan et al., 2001).

Much recent work supports the idea that interactions between the $\mathrm{Ca}^{2+}$ transport mechanisms of ER and mitochondria determine how these organelles cooperate or compete to modulate cytoplasmic $\mathrm{Ca}^{2+}$ signals (Hajnoczky et al., 2000; Rizzuto et al., 2000). Transfer of $\mathrm{Ca}^{2+}$ from the ER to the mitochondrion is the general (but not universal; Hoth et al., 1997; Hongpaisan et al., 2001) direction of transport. As noted previously (Pozzo-Miller et al., 2000), comparison of the time courses of $\mathrm{Ca}^{2+}$ transport by dendritic mitochondria and ER shows that these organelles accumulate and release $\mathrm{Ca}^{2+}$ in distinct and complementary time domains (Fig. 4), raising the possibility of a cooperative relationship. Mutual interdependence also is suggested by experiments showing that thapsigargin inhibition of $\mathrm{ER} \mathrm{Ca}^{2+}$ uptake greatly enhances mitochondrial $\mathrm{Ca}^{2+}$ uptake (Pozzo-Miller et al., 1997). It is not clear whether the interactions underlying ER/mitochondria coupling are direct, as proposed for nonexcitable cells (Rizzuto et al., 1998), or mediated via changes in global $\left[\mathrm{Ca}^{2+}\right]_{\mathrm{i}}$. In either case any Ca "shuttling" at longer times in CA3 dendrites must be from mitochondria to ER, because dendritic ER retains its $\mathrm{Ca}$ load much longer than do mitochondria. Although the details of such interactions remain to be fully understood, it is clear that the ER and mitochondria of pyramidal dendrites play a fundamental role in shaping dendritic calcium signals during synaptically driven neuronal activity.

\section{REFERENCES}

Albrecht MA, Colegrove SL, Hongpaisan J, Pivovarova NB, Andrews SB, Friel DD (2001) Multiple modes of calcium-induced calcium release in sympathetic neurons I: attenuation of endoplasmic reticulum $\mathrm{Ca}^{2+}$ accumulation at low $\left[\mathrm{Ca}^{2+}\right]_{\mathrm{i}}$ during weak depolarization. J Gen Physiol 118:83-100.

Andrews SB, Leapman RD, Landis DM, Reese TS (1988) Activity- 
dependent accumulation of calcium in Purkinje cell dendritic spines. Proc Natl Acad Sci USA 85:1682-1685.

Babcock DF, Hille B (1998) Mitochondrial oversight of cellular $\mathrm{Ca}^{2+}$ signaling. Curr Opin Neurobiol 8:398-404

Babcock DF, Herrington J, Goodwin PC, Park YB, Hille B (1997) Mitochondrial participation in the intracellular $\mathrm{Ca}^{2+}$ network. J Cell Biol 136:833-844.

Berridge MJ (1998) Neuronal calcium signaling. Neuron 21:13-26.

Bindokas VP, Lee CC, Colmers WF, Miller RJ (1998) Changes in mitochondrial function resulting from synaptic activity in the rat hippocampal slice. J Neurosci 18:4570-4587.

Brocard JB, Tassetto M, Reynolds IJ (2001) Quantitative evaluation of mitochondrial calcium content in rat cortical neurones following a glutamate stimulus. J Physiol (Lond) 531:793-805.

Buchanan RA, Leapman RD, O'Connell MF, Reese TS, Andrews SB (1993) Quantitative scanning transmission electron microscopy of ultrathin cryosections: subcellular organelles in rapidly frozen liver and cerebellar cortex. J Struct Biol 110:244-255.

Buckman JF, Reynolds IJ (2001) Spontaneous changes in mitochondrial membrane potential in cultured neurons. J Neurosci 21:5054-5065.

Budd SL, Nicholls DG (1996) Mitochondria, calcium regulation, and acute glutamate excitotoxicity in cultured cerebellar granule cells. J Neurochem 67:2282-2291.

Callaway JC, Ross WN (1997) Spatial distribution of synaptically activated sodium concentration changes in cerebellar Purkinje neurons. J Neurophysiol 77:145-152.

Colegrove SL, Albrecht MA, Friel DD (2000) Quantitative analysis of mitochondrial $\mathrm{Ca}^{2+}$ uptake and release pathways in sympathetic neurons. Reconstruction of the recovery after depolarization-evoked $\left[\mathrm{Ca}^{2+}\right]_{\mathrm{i}}$ elevations. J Gen Physiol 115:371-388.

Collins TJ, Berridge MJ, Lipp P, Bootman MD (2002) Mitochondria are morphologically and functionally heterogeneous within cells. EMBO J 21:1616-1627.

David G (1999) Mitochondrial clearance of cytosolic $\mathrm{Ca}^{2+}$ in stimulated lizard motor nerve terminals proceeds without progressive elevation of mitochondrial matrix $\left[\mathrm{Ca}^{2+}\right]$. J Neurosci 19:7495-7506.

David G, Barrett JN, Barrett EF (1998) Evidence that mitochondria buffer physiological $\mathrm{Ca}^{2+}$ loads in lizard motor nerve terminals. J Physiol (Lond) 509:59-65.

Duchen MR (1999) Contributions of mitochondria to animal physiology: from homeostatic sensor to calcium signaling and cell death. J Physiol (Lond) 516:1-17.

Emptage N, Bliss TV, Fine A (1999) Single synaptic events evoke NMDA receptor-mediated release of calcium from internal stores in hippocampal dendritic spines. Neuron 22:115-124.

Friel DD (2000) Mitochondria as regulators of stimulus-evoked calcium signals in neurons. Cell Calcium 28:307-316.

Friel DD, Tsien RW (1994) An FCCP-sensitive $\mathrm{Ca}^{2+}$ store in bullfrog sympathetic neurons and its participation in stimulus-evoked changes in $\left[\mathrm{Ca}^{2+}\right]_{\mathrm{i}}$. J Neurosci 14:4007-4024.

Gähwiler BH, Capogna M, Debanne D, McKinney RA, Thompson SM (1997) Organotypic slice cultures: a technique has come of age. Trends Neurosci 20:471-477.

Garaschuk O, Yaari Y, Konnerth A (1997) Release and sequestration of calcium by ryanodine-sensitive stores in rat hippocampal neurones. J Physiol (Lond) 502:13-30.

Gunter TE, Pfeiffer DR (1990) Mechanisms by which mitochondria transport calcium. Am J Physiol 258:C755-C786.

Gunter TE, Buntinas L, Sparagna G, Eliseev R, Gunter K (2000) Mitochondrial calcium transport: mechanisms and functions. Cell Calcium 28:285-296.

Hajnoczky G, Csordas G, Madesh M, Pacher P (2000) The machinery of local $\mathrm{Ca}^{2+}$ signaling between sarco-endoplasmic reticulum and mitochondria. J Physiol (Lond) 529:69-81.

Helmchen F (1999) Dendrites as biochemical compartments. In: Dendrites (Stuart G, Spruston N, Häusser M, eds), pp 161-192. New York: Oxford UP.

Helmchen F, Imoto K, Sakmann B (1996) $\mathrm{Ca}^{2+}$ buffering and action potential-evoked $\mathrm{Ca}^{2+}$ signaling in dendrites of pyramidal neurons. Biophys J 70:1069-1081.

Herrington J, Park YB, Babcock DF, Hille B (1996) Dominant role of mitochondria in clearance of large $\mathrm{Ca}^{2+}$ loads from rat adrenal chromaffin cells. Neuron 16:219-228.

Hongpaisan J, Pivovarova NB, Colegrove SL, Leapman RD, Friel DD, Andrews SB (2001) Multiple modes of calcium-induced calcium release in sympathetic neurons II: a $\left[\mathrm{Ca}^{2+}\right]_{\mathrm{i}}$ - and location-dependent transition from endoplasmic reticulum $\mathrm{Ca}$ accumulation to net $\mathrm{Ca}$ release. J Gen Physiol 118:101-112.

Hoth M, Fanger CM, Lewis RS (1997) Mitochondrial regulation of store-operated calcium signaling in $\mathrm{T}$ lymphocytes. J Cell Biol 137:633-648.

Jaffe DB, Johnston D, Lasser-Ross N, Lisman JE, Miyakawa N, Ross WN (1992) The spread of $\mathrm{Na}^{+}$spikes determines the pattern of dendritic $\mathrm{Ca}^{2+}$ entry into hippocampal neurons. Nature 357:244-246.
Johnston D, Magee JC, Colbert CM, Christie BR (1996) Active properties of neuronal dendrites. Annu Rev Neurosci 19:165-186.

Kapur A, Yeckel M, Johnston D (2001) Hippocampal mossy fiber activity evokes $\mathrm{Ca}^{2+}$ release in CA3 pyramidal neurons via a metabotropic glutamate receptor pathway. Neuroscience 107:59-69.

Kiedrowski L, Brooker G, Costa E, Wroblewski JT (1994) Glutamate impairs neuronal calcium extrusion while reducing sodium gradient. Neuron 12:295-300.

Kitazawa T, Shuman H, Somlyo AP (1983) Quantitative electron probe analysis: problems and solutions. Ultramicroscopy 11:251-262.

Magee JC, Christofi G, Miyakawa H, Christie BC, Lasser-Ross N, Johnston D (1995) Subthreshold synaptic activation of voltage-gated $\mathrm{Ca}^{2+}$ channels mediates a localized $\mathrm{Ca}^{2+}$ influx into dendrites of hippocampal pyramidal neurons. J Neurophysiol 74:1335-1346.

Meldolesi J (2001) Rapidly exchanging $\mathrm{Ca}^{2+}$ stores in neurons: molecular, structural, and functional properties. Prog Neurobiol 65:309-338.

Meldolesi J, Grohovaz F (2001) Total calcium ultrastructure: advances in excitable cells. Cell Calcium 30:1-8.

Montero M, Alonso MT, Carnicero E, Cuchillo-Ibanez I, Albilos A, Garcia AG, Garcia-Sancho J, Alvarez J (2000) Chromaffin cell stimulation triggers fast millimolar mitochondrial $\mathrm{Ca}^{2+}$ transients that modulate secretion. Nat Cell Biol 2:57-61.

Nakamura T, Barbara JG, Nakamura K, Ross WN (1999) Synergistic release of $\mathrm{Ca}^{2+}$ from $\mathrm{IP}_{3}$-sensitive stores evoked by synaptic activation of mGluRs paired with backpropagating action potentials. Neuron 24:727-737.

Nakamura T, Nakamura K, Lasser-Ross N, Barbara JG, Sandler VM, Ross WN (2000) Inositol 1,4,5-trisphosphate $\left(\mathrm{IP}_{3}\right)$-mediated $\mathrm{Ca}^{2+}$ release evoked by metabotropic agonists and backpropagating action potentials in hippocampal CA1 pyramidal neurons. J Neurosci 20:8365-8376.

Nicholls DG, Budd SL (2000) Mitochondria and neuronal survival. Physiol Rev 80:315-360.

Peng Y-Y (1998) Effects of mitochondrion on calcium transients at intact presynaptic terminals depend on frequency of nerve firing. J Neurophysiol 80:186-195.

Petrozzino JJ, Pozzo-Miller LD, Connor JA (1995) Micromolar $\mathrm{Ca}^{2+}$ transients in dendritic spines of hippocampal pyramidal neurons in brain slice. Neuron 14:1223-1231.

Pivovarova NB, Hongpaisan J, Andrews SB, Friel DD (1999) Depolarization-induced mitochondrial $\mathrm{Ca}$ accumulation in sympathetic neurons: spatial and temporal characteristics. J Neurosci 19:6372-6384.

Pozzan T, Rizzuto R (2000) The renaissance of mitochondrial calcium transport. Eur J Biochem 267:5269-5273.

Pozzo-Miller LD, Petrozzino JJ, Mahanty NK, Connor JA (1993) Optical imaging of cytosolic calcium, electrophysiology, and ultrastructure in pyramidal neurons of organotypic slice cultures from rat hippocampus. NeuroImage 1:109-120.

Pozzo-Miller LD, Mahanty NK, Connor JA, Landis DMD (1994) Spontaneous pyramidal cell death in organotypic slice cultures from rat hippocampus is prevented by glutamate receptor antagonists. Neuroscience 63:471-487.

Pozzo-Miller LD, Petrozzino JJ, Golarai G, Connor JA (1996) $\mathrm{Ca}^{2+}$ release from intracellular stores induced by afferent stimulation of pyramidal neurons in hippocampal slice. J Neurophysiol 76:554-562.

Pozzo-Miller LD, Pivovarova NB, Leapman RD, Buchanan RA, Reese TS, Andrews SB (1997) Activity-dependent calcium sequestration in dendrites of hippocampal neurons in brain slices. J Neurosci 17:8729-8738.

Pozzo-Miller LD, Connor JA, Andrews SB (2000) Microheterogeneity of calcium signaling in dendrites. J Physiol (Lond) 525:53-61.

Rae MG, Martin DJ, Collingridge GL, Irving AJ (2000) Role of $\mathrm{Ca}^{2+}$ stores in metabotropic L-glutamate receptor-mediated supralinear $\mathrm{Ca}^{2+}$ signaling in rat hippocampal neurons. J Neurosci 20:8628-8636.

Regehr WG, Connor JA, Tank DW (1989) Optical imaging of calcium accumulation in hippocampal pyramidal cells during synaptic activation. Nature 341:533-536.

Reynolds IJ (1999) Mitochondrial membrane potential and the permeability transition in excitotoxicity. Ann NY Acad Sci 893:33-41.

Rizzuto R, Pinton P, Carrington W, Fay FS, Fogarty KE, Lifshitz LM, Tuft RA, Pozzan T (1998) Close contacts with the endoplasmic reticulum as determinants of mitochondrial $\mathrm{Ca}^{2+}$ responses. Science 280:1763-1766.

Rizzuto R, Bernardi P, Pozzan T (2000) Mitochondria as all-round players of the calcium game. J Physiol (Lond) 529[Pt 1]:37-47.

Roomans GM, Von Euler A (1996) X-ray microanalysis in cell biology and cell pathology. Cell Biol Int 20:103-109.

Rose CR, Konnerth A (2001) NMDA receptor-mediated $\mathrm{Na}^{+}$signals in spines and dendrites. J Neurosci 21:4207-4214.

Seymour-Laurent KJ, Barish ME (1995) Inositol 1,4,5-trisphosphate and ryanodine receptor distributions and patterns of acetylcholine- and caffeine-induced calcium release in cultured mouse hippocampal neurons. J Neurosci 15:2592-2608. 
Somlyo AP (1985) Cell calcium measurement with electron probe and electron energy loss analysis. Cell Calcium 6:197-212.

Somlyo AP, Urbanics R, Vadasz G, Kovach AG, Somlyo AV (1985) Mitochondrial calcium and cellular electrolytes in brain cortex frozen in situ: electron probe analysis. Biochem Biophys Res Commun 132:1071-1078.

Spruston N, Schiller Y, Stuart G, Sakmann B (1995) Activity-dependent action potential invasion and calcium influx into hippocampal CA1 dendrites. Science 268:297-300.

Stoppini L, Buchs PA, Muller D (1991) A simple method for organotypic cultures of nervous tissue. J Neurosci Methods 37:173-182.

Stout AK, Raphael HM, Kanterewicz BI, Klann E, Reynolds IJ (1998) Glutamate-induced neuron death requires mitochondrial calcium uptake. Nat Neurosci 1:366-373.

Tang Y, Zucker RS (1997) Mitochondrial involvement in post-tetanic potentiation of synaptic transmission. Neuron 18:483-491.

Taylor CP, Weber ML, Gaughan CL, Lehning EJ, LoPachin RM (1999) Oxygen/glucose deprivation in hippocampal slices: altered intraneuronal elemental composition predicts structural and functional damage. J Neurosci 19:619-629.

Thayer SA, Miller RJ (1990) Regulation of the intracellular free calcium concentration in single rat dorsal root ganglion neurones in vitro. J Physiol (Lond) 425:85-115.

Tse FW, Tse A, Hille B, Horstmann H, Almers W (1997) Local Ca ${ }^{2+}$ release from internal stores controls exocytosis in pituitary gonadotrophs. Neuron 18:121-132.

Wang GJ, Thayer SA (1996) Sequestration of glutamate-induced Ca ${ }^{2+}$ loads by mitochondria in cultured rat hippocampal neurons. J Neurophysiol 76:1611-1621.

White RJ, Reynolds IJ (1995) Mitochondria and $\mathrm{Na}^{+} / \mathrm{Ca}^{2+}$ exchange buffer glutamate-induced calcium loads in cultured cortical neurons. J Neurosci 15:1318-1328.

Yeckel MF, Kapur A, Johnston D (1999) Multiple forms of LTP in hippocampal CA3 neurons use a common postsynaptic mechanism. Nat Neurosci 2:625-633.

Zenisek D, Matthews G (2000) The role of mitochondria in presynaptic calcium handling at a ribbon synapse. Neuron 25:229-237.

Zhong N, Beaumont V, Zucker RS (2001) Roles for mitochondrial and reverse mode $\mathrm{Na}^{+} / \mathrm{Ca}^{2+}$ exchange and the plasmalemma $\mathrm{Ca}^{2+}$ ATPase in post-tetanic potentiation at crayfish neuromuscular junctions. J Neurosci 21:9598-9607. 